\title{
Ultrafine Grained Ferrite Formed by Interrupted Hot Torsion Deformation of Plain Carbon Steel
}

\author{
G. L. KELLY, H. BELADI and P. D. HODGSON \\ School of Engineering and Technology, Deakin University, Geelong Vic. 3217, Australia.
}

(Received on May 20, 2002; accepted in final form on October 18, 2002)

\begin{abstract}
A plain carbon steel was deformed using a hot torsion deformation simulator. A schedule known to produce strain-induced ferrite was used with the strain interrupted for increasing intervals of time to determine the effect of an isothermal hold on the final microstructure. Microscopy and electron back-scattered diffraction (EBSD) were used to analyse the changes that occurred in the partially transformed microstructure during the hold and the subsequent applied strain. The strain-induced ferrite coarsened during the hold and this coarsened ferrite was refined during the second deformation. These results were compared to those obtained for a different plain carbon steel deformed in single pass rolling close to the $\mathrm{Ar}_{3}$ temperature.
\end{abstract}

KEY WORDS: ultra-fine ferrite; strain-induced transformation; hot torsion; rolling; post-deformation softening.

\section{Introduction}

One of the most successful methods used to produce ultrafine ferrite (UFF) in the laboratory is strain-induced transformation. ${ }^{1-3)}$ The ultimate goal of the worldwide research being undertaken in this area is to discover how the grain refinement methods successfully applied in the laboratory can be adapted to commercial processes. Strain-induced transformation of austenite to UFF involves large strains, typically $2-5$, being applied to the austenite in a critical temperature range. The critical temperature of deformation used in the laboratory is usually at, or just above, the $\mathrm{Ar}_{3}{ }^{3)}$ although some recent work has demonstrated that strain-induced transformation is possible provided the temperature is selected so that the austenite is metastable, i.e. between $\mathrm{Ae}_{3}$ and $\mathrm{Ar}_{3}{ }^{4}{ }^{4,5)}$ It is also possible to form ultrafine ferrite at deformation temperatures below $\mathrm{Ar}_{3}$, where bainite would usually form, if fast cooling to the deformation temperature is applied. ${ }^{6,7)}$

There is strong evidence that the key to strain-induced transformation to UFF is development of particular features in the deformation structure of the austenite. ${ }^{8)}$ Insight into the likely nucleation sites of UFF has been gained by comparison of the deformation structure in an austenitic $\mathrm{Fe}-\mathrm{Ni}$ model alloy with UFF formed in a low carbon steel deformed under the same conditions. The most probable nucleation sites for UFF were identified as features such as microshear bands and microbands. ${ }^{8}$ While this work has led to a greater understanding of how UFF is formed, it has also raised the question of how softening processes, such as those occurring during interpass times, will affect the deformation structure of the austenite and hence formation of UFF.

Grain refinement can also be achieved by deformation of austenite or ferrite through mechanisms such as dynamic recrystallisation (DRX) or metadynamic recrystallisation (MDRX). The commercial exploitation of DRX has been investigated mainly by Jonas and co-workers. ${ }^{9,10)}$ UFF has been produced by DRX occurring during rolling. ${ }^{11)}$ Another potential refinement mechanism is subgrain rotation or continuous recrystallisation during deformation. It has recently been recognized that this mechanism can create new, high misorientation grain boundaries in aluminium ${ }^{12}$ and it is possible that this could occur in ferrite.

This work examines the impact of interruption of deformation on strain-induced transformation of austenite to ferrite and explores one potential mechanism for further refining the microstructure that has been partially transformed to strain-induced ferrite.

\section{Method and Materials}

A hot torsion deformation simulator with induction heating and water quench facilities was used to deform an AISI 1010 plain carbon steel $(0.06-0.13 \mathrm{C}, 0.25-0.60 \mathrm{Mn})$. The samples had a gauge length of $10 \mathrm{~mm}$ and a gauge diameter of $6.7 \mathrm{~mm}$. The schedule involved austenitisation at $1200^{\circ} \mathrm{C}$, followed by air-cooling at a rate of approximately $4^{\circ} \mathrm{C} / \mathrm{s}$ to $760^{\circ} \mathrm{C}$ (which had been experimentally determined to be the $\mathrm{Ar}_{3}$ ), then isothermal deformation at a true strain rate of $3 \mathrm{~s}^{-1}$. Previous work ${ }^{13)}$ had shown that a strain of 3 , applied under these conditions would result in strain-induced UFF being formed with complete transformation to ferrite on the surface of the torsion sample. The microstructures at the gauge length surface obtained under these conditions consisted of equiaxed ultrafine ferrite grains with a homogeneous dispersion of fine carbides located grain boundaries and triple points. To assess the impact of inter- 
rupting the deformation, the sample was strained to 1.5 , held isothermally, then a second strain of 1.5 was applied. The isothermal hold times were varied between 0.2 and 10 s. While heated, the sample was enclosed in a quartz tube with a positive pressure of Argon gas to prevent decarburisation. Samples were water quenched at various stages of the process to preserve the resulting microstructures for metallographic examination. The temperature was monitored using a thermocouple placed at the end of the gauge length, in the centre of the sample.

Strain and strain rate vary along the radius of torsion samples with the surface of the gauge length undergoing the greatest deformation. The strain and strain rate were calculated for the surface of the gauge length. To compare areas that had been subjected to the same deformation conditions, only the microstructures within $100 \mu \mathrm{m}$ of the longitudinal surface of the gauge length were considered.

The fractional softening occurring during the isothermal hold was calculated by comparing the flow curves obtained from successive deformations using the method described in previous work. ${ }^{14)}$

Samples were examined using a field emission scanning electron microscope fitted with electron back-scattered diffraction (EBSD). EBSD was carried out using step sizes of 0.2 or $0.5 \mu \mathrm{m}$ depending on the grain size of the sample being analysed. Ferrite grain sizes were measured using the linear intercept method with EBSD being used to distinguish the ferrite grain boundaries with misorientation angles more than $10^{\circ}$ using HKL Technology Channel 5. The analysis was restricted to the ferrite phase only with areas of the sample that had transformed to martensite being excluded.

These results were compared with wedge samples of AISI 1040 plain carbon steel $(0.37-0.40 \mathrm{C}, 0.60-0.90 \mathrm{Mn})$ which had been rolled in a laboratory mill in a single pass. The mill has rolls of $365 \mathrm{~mm}$ diameter and a rolling speed of $15 \mathrm{rpm}$ was used. The overall sample size was 140 $\mathrm{mm} \times 20 \mathrm{~mm} \times 8 \mathrm{~mm}$ with an included angle of about $4^{\circ}$. The samples were austenitised then cooled slowly to the deformation temperature. The sample temperature at the beginning of rolling was close to the $\mathrm{Ar}_{3}$ and a $70 \%$ reduction was applied.

\section{Results}

\subsection{Hot Torsion}

\subsubsection{Softening}

Softening fractions were calculated for interdeformation times ranging from 0.2 to $10 \mathrm{~s}$ using the method described previously. ${ }^{14)}$ After a $0.2 \mathrm{~s}$ interval, $21 \%$ softening had occurred with little additional softening taking place until after $0.5 \mathrm{~s}$. Increasing the isothermal hold time to $10 \mathrm{~s}$ increased the softening fraction to $72 \%$ (Fig. 1). The softening curve had a typical sigmoidal shape.

There was a very small amount of proeutectoid ferrite present in the samples quenched immediately after a strain of 1.5 was applied. This indicates that the deformation temperature was slightly below $\mathrm{Ar}_{3}$. The measured softening could be due to recovery or recrystallisation of the austenite and proeutectoid ferrite that existed prior to deformation. Further tranformation of austenite to ferrite during the

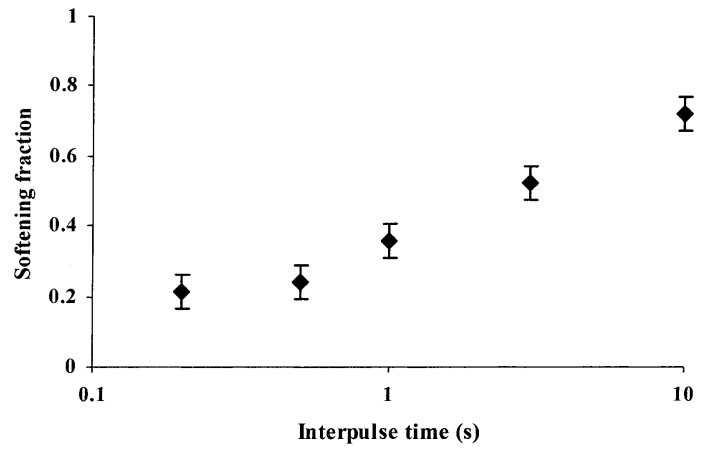

Fig. 1. Softening kinetics of AISI 1010 steel during an isothermal hold following deformation at $760^{\circ} \mathrm{C}, \dot{\varepsilon}=3 \mathrm{~s}^{-1}$, $\varepsilon=1.5$.

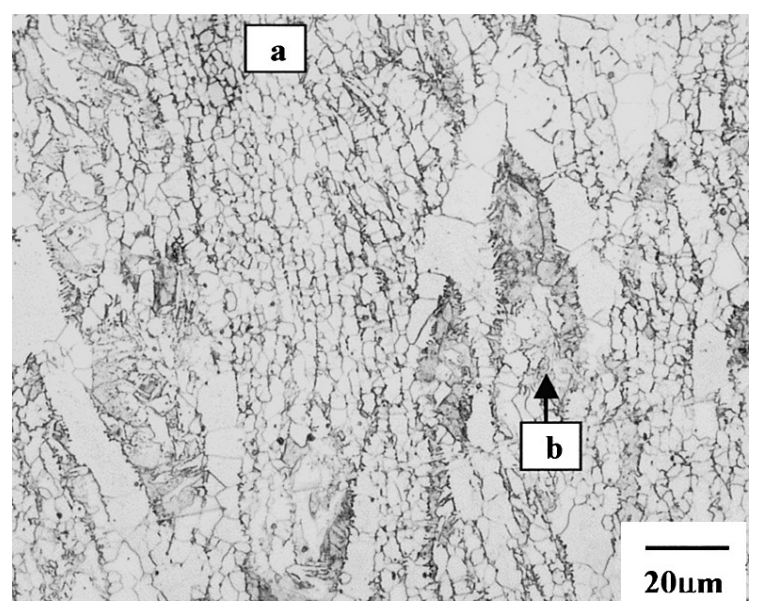

Fig. 2. AISI 1010 steel deformed in hot torsion at $760^{\circ} \mathrm{C}, \dot{\varepsilon}=3$ $\mathrm{s}^{-1}, \varepsilon=1.5$ and water quenched immediately. (a) An area where transformation is almost complete, (b) an area with very little transformation prior to the water quench.

isothermal hold would also lead to an apparent softening as ferrite is much softer than austenite under these deformation conditions. There was no attempt in the current work to separate the contributions of these features.

\subsubsection{Microstructures}

-Sample 1: $\varepsilon=1.5$, Immediate Water Quench

After a strain of 1.5 , the microstructure consisted of a small amount of proeutectoid ferrite delineating the prior austenite grain boundaries and rafts of fine, equiaxed ferrite traversing the austenite grains. During the water quench, any remaining austenite was transformed to martensite. The rafts of ferrite were approximately parallel and consisted of rows of fine grains, less than $2 \mu \mathrm{m}$ in size. Some austenite grains had a much greater volume of ferrite rafts than others (Fig. 2). In both cases, the size of the ferrite grains was similar, suggesting that transformation proceeded by the nucleation of new ferrite grains in the austenite and not by significant coarsening of the ferrite.

Previous work by one of the authors explains the formation of the linear arrays of strain-induced ferrite. ${ }^{8,15)}$ In that work, a $\mathrm{Ni}-30 \mathrm{wt} \% \mathrm{Fe}$ alloy with the same stacking fault energy as austenite was used as a model to gain insight into the dislocation substructures of the deformed austenite. The $\mathrm{Ni}-\mathrm{Fe}$ model alloy and steel were subjected to the same deformation conditions and quenched. Comparison of the 


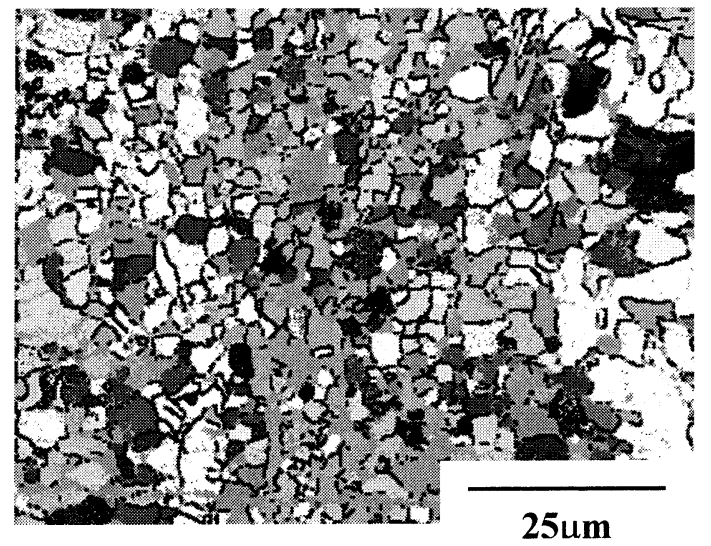

Fig. 3. EBSD image of Sample 1 showing grain boundaries with misorientation angles greater than $10^{\circ}$, a step size of 0.2 $\mu \mathrm{m}$ was used. The section is the same as that in Fig. 2.

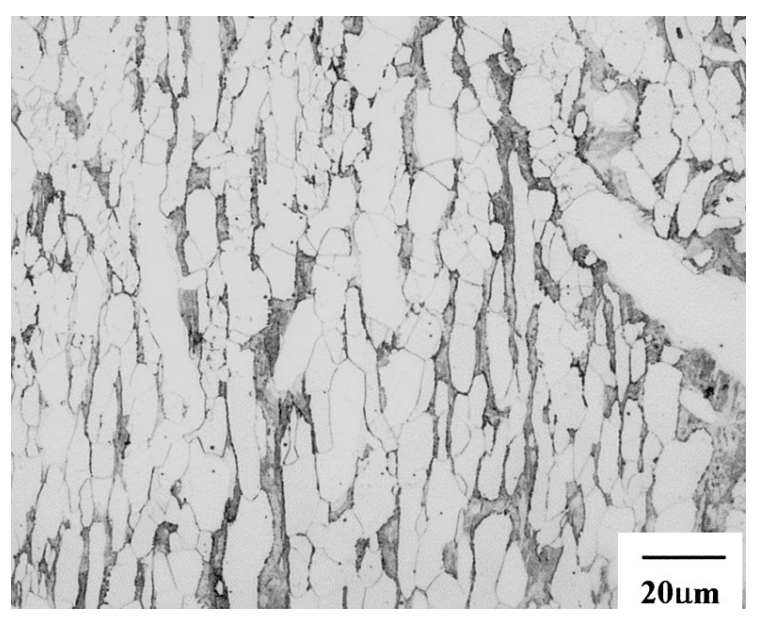

Fig. 4. AISI 1010 steel deformed in hot torsion at $760^{\circ} \mathrm{C}, \dot{\varepsilon}=3$ $\mathrm{s}^{-1}, \quad \varepsilon=1.5$, held isothermally for $10 \mathrm{~s}$ and water quenched immediately.

model alloy and the steel showed that the spacing and arrangement of strain-induced ferrite rafts corresponded closely with the locations of deformation features such as microshear bands in the austenite. ${ }^{8,15)}$

In all samples, EBSD was used to measure the ferrite grain sizes and the misorientation angles between adjacent ferrite grains. An area where transformation from austenite to ferrite was almost complete was selected for this analysis. Grain boundaries with misorientation angles greater than $10^{\circ}$ are marked as heavy lines (Fig. 3). Note that the ferrite rafts are oriented approximately vertically in the image. These misorientation angles will be discussed further in the next section.

-Sample 2: $\varepsilon=1.5$, Isothermal Hold for $10 \mathrm{~s}$, Water Quench

After a strain of 1.5 and an isothermal hold for $10 \mathrm{~s}$, the microstructure consisted of proeutectoid ferrite and coarsened ferrite on the rafts with small amounts of austenite remaining which transformed to martensite during the quench (Fig. 4). The ferrite rafts were again linear and parallel but the mean ferrite grain size increased to $4.1 \mu \mathrm{m}$.

The ferrite grain size distribution broadened considerably during the isothermal hold (Fig. 5). After the immediate water quench (Sample 1), the ferrite grain size distribution

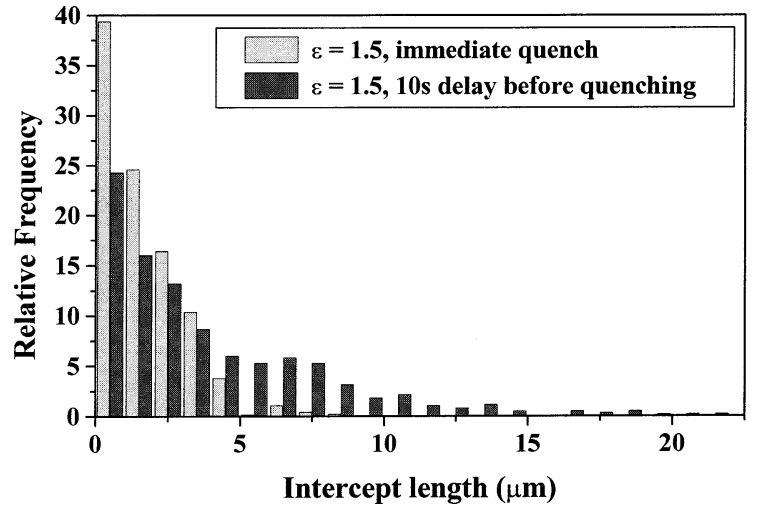

Fig. 5. Mean intercept length for ferrite grains in Samples 1 and 2 as determined from EBSD analysis. Measurements were made in random directions.

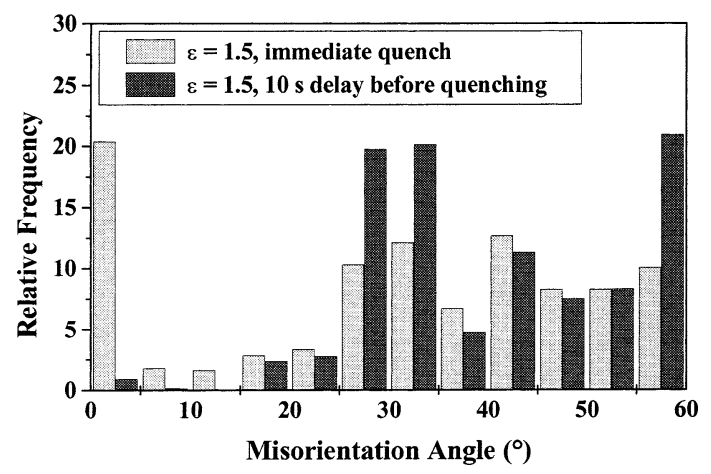

Fig. 6. Distribution of misorientation angles between adjacent ferrite grains for Samples 1 and 2 as determined from EBSD analysis.

was very narrow, extending to approximately $7 \mu \mathrm{m}$. After the $10 \mathrm{~s}$ isothermal hold, there were a small number of ferrite grains ranging in size up to $30 \mu \mathrm{m}$. During the isothermal hold, the softening fraction increased from 21 to $72 \%$ (Fig. 1). This softening includes a significant contribution from the austenite to ferrite phase transformation. There were few fine ferrite grains present, suggesting that the phase transformation continued primarily by coarsening of the ferrite already present, not further nucleation of new grains. The ferrite grains on the rafts were no longer equiaxed with preferential growth occurring parallel to the raft. This is thought to be likely due to higher diffusion rates along the linear defects that the ferrite rafts formed on. ${ }^{16)}$

There has been a significant change in the distribution of misorientation angles between adjacent ferrite grains. When the sample was quenched immediately after deformation there was a very high proportion of low misorientation angles. Following the $10 \mathrm{~s}$ isothermal hold, there were few boundaries remaining with misorientation angles less than $15^{\circ}$ (Fig. 6). It appears that the coarsening of the ferrite grains on the rafts progresses by coalescence of ferrite grains, this process favouring removal of many of the low misorientation angle boundaries.

If martensite was included in the analysis, the frequency of low misorientation angle boundaries greatly increased. While every effort was made to exclude martensite from the analysis, there is the possibility that the high proportion 


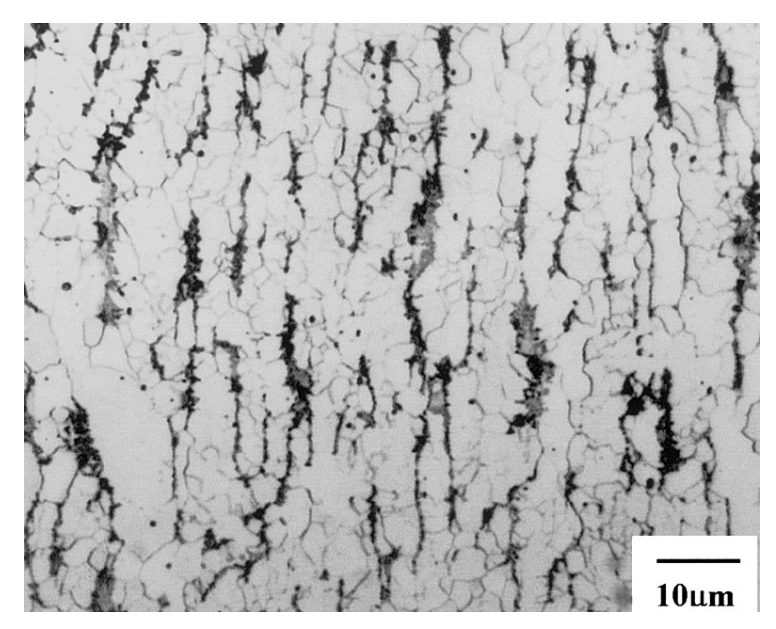

Fig. 7. AISI 1010 steel deformed in hot torsion at $760^{\circ} \mathrm{C}, \dot{\varepsilon}=3$ $\mathrm{s}^{-1}, \varepsilon=1.5$, isothermal hold for $10 \mathrm{~s}, \varepsilon_{2}=1.5$ and water quenched immediately.

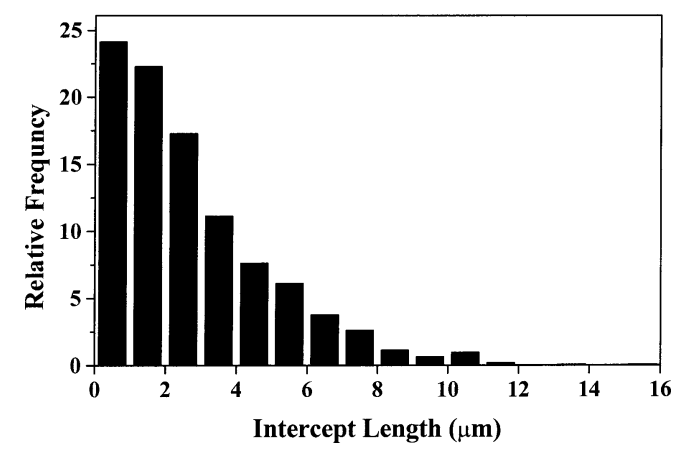

Fig. 8. Mean intercept length for ferrite grains in Sample 3 as determined from EBSD analysis.

of low misorientation angle boundaries in Sample 1 is partially contributed to by the presence of martensite in the sample. Previous work has, however, shown that low misorentation angle boundaries are relatively common in strain-induced ferrite resulting from hot torsion deformation. ${ }^{17)}$

- Sample 3: $\varepsilon_{1}=1.5$, Isothermal Hold $10 \mathrm{~s}, \varepsilon_{2}=1.5$

A second strain of 1.5 was applied after the isothermal hold. The microstructure was refined (Fig. 7) compared to the starting microstructure before the second strain (Fig. 4). Bands of ferrite grains were arranged in a linear fashion. Dark areas consisting of carbides and possibly martensite were also linear. The size and spacing of these dark areas suggests that they are the product of the austenite which was present between the coarsened ferrite rafts prior to the second strain being applied. The mean ferrite grain size has been reduced to $2.6 \mu \mathrm{m}$ with the ferrite grain size distribution much narrower than after the $10 \mathrm{~s}$ hold (Fig. 8). The coarsened proeutectoid ferrite present at the beginning of the second deformation (Fig. 4) has also been refined and can no longer be distinguished.

The microstructure present prior to the second deformation consisted of coarsened proeutectoid ferrite and intragranular ferrite grains with a small amount of austenite between the rafts (Fig. 4). The second deformation, therefore, refined the coarse ferrite present at the end of the isothermal hold. EBSD analysis provides some insight into the

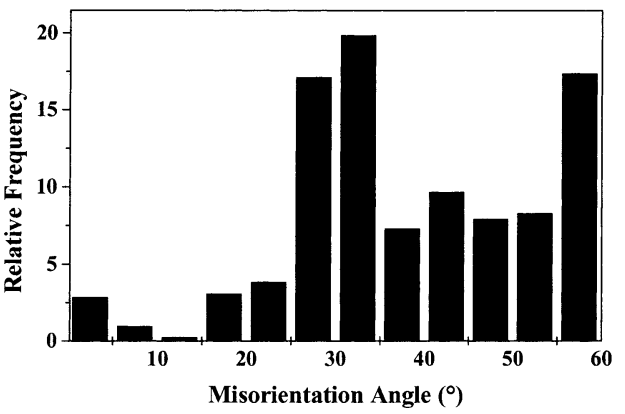

Fig. 9. Distribution of misorientation angles between adjacent ferrite grains for Sample 3 as determined from EBSD analysis.

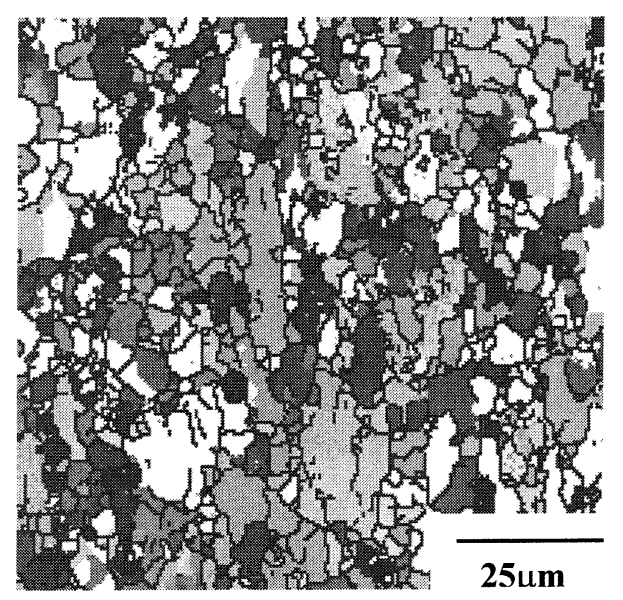

Fig. 10. EBSD scan of Sample 3 showing incomplete grain boundaries in some of the larger ferrite grains, a step size of $0.5 \mu \mathrm{m}$ was used.

possible mechanism of ferrite refinement. Firstly, the majority of the misorientation angles are above $15^{\circ}$ (Fig. 9). Secondly, there are a number of incomplete grain boundaries, i.e. isolated high angle grain boundary segments present in the larger ferrite grains (Fig. 10).

DRX occurs in ferrite at lower $Z$ values, as $Z$ increases, there is a transition from DRX to dynamic recovery (DRV). The transition from DRX to DRV in high purity iron was found to be $\sim 10^{13}{ }^{18)}$ while Tsuji et al. found that the transition occurred at $\sim 10^{11} \mathrm{~s}^{-1}$ for hot worked ferrite in IF steel, $\left.{ }^{19}\right)$ i.e. increasing the carbon content decreased the transition value. The hot torsion deformation conditions used for the present work correspond to a Zener-Hollomon parameter of $4.4 \times 10^{14} \mathrm{~s}^{-1}(Z=\dot{\varepsilon} \cdot \exp (Q / R T)$, where $Q$ is the activation energy for deformation, $280 \mathrm{~kJ} / \mathrm{mol},{ }^{20)} R$ is the gas constant and $T$ is the temperature in K.). Taking the previous studies ${ }^{18,19)}$ into account, it is unlikely that the ferrite refinement observed is due to DRX since the ZenerHollomon parameter used in the present work is too high.

The refinement mechanism operating during the second deformation appears to be similar to that shown to generate high angle grain boundaries during hot torsion deformation of alumium ${ }^{12)}$ and suggested to occur in ferrite, ${ }^{21)}$ which is currently termed continuous dynamic recrystallisation. In the case of the steel here, subgrains would form in the larger ferrite grains as the second deformation proceeded. As 


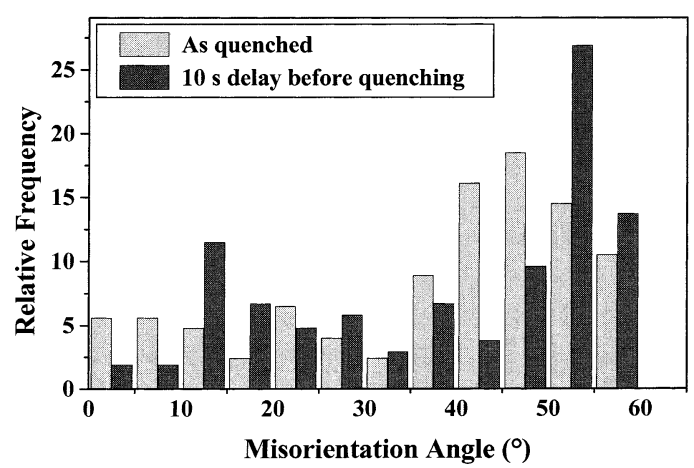

Fig. 11. Distribution of misorientation angles between adjacent ferrite grains for samples rolled then water quenched immediately and after a $10 \mathrm{~s}$ delay as determined from EBSD analysis.

the strain increased, dislocations would accumulate in the subgrain boundaries and the misorientations across these boundaries would increase. While this mechanism provides an explanation for the EBSD results (Fig. 9) and the observed microstructure (Fig. 10), a much more detailed study is required before the grain refinement during the second deformation can be confidently attributed to continuous dynamic recrystallisation.

\subsection{Comparison with Rolled Samples}

The major difference between the hot torsion schedule used in this work and laboratory rolling is the quenching supplied by roll chill during deformation by rolling. The following is a brief discussion comparing preliminary results from a parallel study using an AISI 1040 steel. The aim of the rolling work was to examine the effect of slow cooling following single pass rolling on the ferrite grain size and orientation. It is acknowledged that the carbon contents of the two steels are very different, however the trends in grain growth following rolling are very similar to those observed during the isothermal hold after hot torsion deformation.

The austenite grain size of the AISI 1040 steel before rolling was $120 \mu \mathrm{m}$. During deformation discrete rafts of strain-induced ferrite grains formed within the austenite grains. The grain size and misorientation angle data were collected from individual ferrite rafts. As found for the steel deformed in hot torsion, the frequency of low misorientation grain boundaries decreases with time after deformation (Fig. 11). In the case of the rolled sample, the low misorientation angle grain boundaries are not as common in the sample quenched early as they were in the hot torsion sample. Previous work by one of the authors ${ }^{22)}$ also found that low misorientation grain boundaries were uncommon in strain-induced ferrite formed during rolling.

Other studies ${ }^{13,22)}$ have shown that strain-induced ferrite formed during rolling is resistant to coarsening, even in the case of ultra low carbon steel. ${ }^{23}$ ) This contrasts with the rapid ferrite grain growth observed in this study during the isothermal hold following hot torsion deformation. In the previous studies of rolling, the transformation from austenite to ferrite was complete at the end of deformation and the microstructure consisted of ultra-fine ferrite with fine carbides dispersed on the grain boundaries, particularly at the triple points. The difference in post deformation coarsening between strain-induced ferrite formed by hot torsion and rolling has been explained as follows. ${ }^{22)}$ The quenching provided by the rolls counters the adiabatic heating so that at the end of rolling the ferrite has spent only a short time at a temperature where significant ferrite grain growth might be expected to occur. In the case of hot torsion, there is no cooling during deformation. This means that the strain-induced ferrite then experiences higher temperatures where ferrite grain growth is more likely.

A similar microstructure to that formed during rolling is obtained when the sample is quenched during torsion. ${ }^{16)}$ The current work also suggests that the large number of low misorientation angle boundaries encourages ferrite grain coalescence resulting in a coarser final microstructure.

\section{Conclusions}

Ferrite formed by strain-induced transformation during hot torsion is characterized by planar arrays or rafts of very fine ferrite grains formed intragranularly in the austenite. There is a significant proportion of low misorientation angle boundaries between adjacent ferrite grains.

Interrupting deformation prevents further strain-induced transformation. The austenite-to-ferrite transformation continues largely by coarsening of the strain-induced ferrite grains formed during deformation. Ferrite grain coalescence occurring during this coarsening removes most of the low misorientation boundaries that are present at the beginning of the isothermal hold.

Further deformation of the coarsened ferrite results in considerable refinement of the ferrite with the creation of new, high misorientation angle grain boundaries. Since the work of other authors ${ }^{18,19)}$ suggests that it is unlikely that DRX occurs under these conditions, it is proposed that this refinement is likely to be due to continuous dynamic recrystallisation.

\section{Acknowledgements}

This project was funded by the Australian Research Council (ARC). The authors also acknowledge the assistance of Mr. John Whale with the hot torsion testing and helpful discussions with Dr. Matthew Barnett.

\section{REFERENCES}

1) R. Priestner: Proc. Thermomechanical Processing of Microalloyed Austenite, ed. by A. J. De Ardo, G. A. Ratz and P. J. Wray, TMSAIME, Warrendale, PA, (1981), 455.

2) J. H. Beynon, R. Gloss and P. D. Hodgson: Mater. Forum, 16 (1992), 37.

3) P. D. Hodgson, M. R. Hickson and R. K. Gibbs: Scr. Mater., 40 (1999), 1179.

4) H. Yada, C-M. Li and H. Yamagata: ISIJ Int., 40 (2000), 200.

5) E. Alonso, F. Hassani and S. Yue: 42nd Mechanical Working and Steel Processing Conf. Proc., Vol. XXXVIII, ISS-AIME, Warrendale, PA, (2000) 515.

6) Y. Adachi, T. Tomida and S. Hinotani: Tetsu-to-Hagané, 85 (1999), 85.

7) Y. Adachi and S. Hinotani: Proc. Int. Symp. on Ultrafine Grained Steels (ISUGS 2001), ed. by S. Takaki and T. Maki, ISIJ, Tokyo, (2001), 84

8) P. J. Hurley, B. C. Muddle and P. D. Hodgson: Mater. Sci. Technol., 16 (2000), 1376.

9) J. J. Jonas: Mater. Sci. Eng. A, 184 (1994), 155.

10) J. J. Jonas: Proc. Int. Conf. on Recrystallisation in Metallic 
Materials, ed. by T. Chandra, TMS-AIME, Warrendale, PA, (1990), 27.

11) H. Yada, Y. Matsumura and K. Nakajima: United States Patent No. 4,466,842, (1984).

12) M. R. Barnett and F. Montheillet: Acta Mater., 50 (2002), 2285.

13) M. R. Hickson, P. J. Hurley, R. K. Gibbs, G. L. Kelly and P. D. Hodgson: Metall. Mater. Trans. A, 33 (2002), 1019.

14) C. Roucoules, P. D. Hodgson, S. Yue and J. J. Jonas: Metall. Trans. A, 25 (1994), 389.

15) P. J. Hurley, P. D. Hodgson and B. C. Muddle: Scr. Mater., 45 (2001), 25.

16) P. J. Hurley and P. D. Hodgson: Mater. Sci. Technol., 17 (2001), 1360 .
17) P. J. Hurley: Ph. D. Thesis, Monash University, Melbourne, (1999).

18) G. Glover and C. M. Sellars: Metall. Trans., 4 (1973), 765.

19) N. Tsuji, T. Saito and T. Maki: Recrystallization '99, ed. by T. Sakai and H. G. Suzuki, The Japan Institute of Metals, Sendai, (1999), 253.

20) M. R. Barnett, G. L. Kelly and P. D. Hodgson: Scr. Mater., 43 (2000), 365.

21) M. R. Barnett, G. L. Kelly and P. D. Hodgson: Metall. Mater. Trans. $A,(2002)$, in press.

22) P. J. Hurley and P. D. Hodgson: Mater. Sci. Eng. A, 302 (2001), 206.

23) P. J. Hurley, B. C. Muddle and P. D. Hodgson: Scr. Mater., 40 (1999), 433. 